\title{
Plasmids for Amoxicillin and Ciprofloxacin Resistance in Escherichia coli Isolate Causing Urinary Tract Infection
}

Sabrina Suhani, Auditi Purkaystha, Musammat Kulsuma Begum, Md. Jahidul Islam and Abul Kalam Azad*

Department of Genetic Engineering \& Biotechnology, Shahjalal University of Science and Technology, Sylhet-3114, Bangladesh

"Corresponding author: Abul Kalam Azad, Shahjalal University of Science and Technology, Sylhet, Bangladesh, Tel: +880 1715 160921 ; E-mail: dakazad-btc@sust.edu Received date: June 07, 2017; Accepted date: June 30, 2017; Published date: July 5, 2017

Copyright: $\odot 2017$ Suhani S, et al. This is an open-access article distributed under the terms of the Creative Commons Attribution License, which permits unrestricted use, distribution, and reproduction in any medium, provided the original author and source are credited.

\begin{abstract}
Background: Escherichia coli causes urinary tract infection (UTI), one of the most frequent bacterial infections in humans, shows resistance to various commonly prescribed antibiotics. This is termed as multi drug resistance, which is increasing among $E$. coli. The multi-drug resistant $E$. coli isolates harbor multiple plasmids that might be responsible for antibiotic resistance. The resistance can be transferred among bacteria through horizontal transfer of the genetic materials.
\end{abstract}

Objectives: We undertook this study 1) to find a link between antibiotic resistance and plasmid of $E$. coli from UTI patients of Sylhet region of Bangladesh 2) to analyze the spread of the plasmid mediated antibiotic resistant gene between $E$. coli isolates.

Methods: Conjugation experiment was carried out in Luria Broth with E. coli DH5a as recipient. For transformation, competent cells were prepared using E. coli DH5a. Plasmid isolation was done by mini alkaline lysis method and plasmid was extracted from agarose gel and transferred to the competent cell.

Results: After conjugation, the donor $E$. coli isolate that showed resistance to amoxicillin (AMX), ciprofloxacin (CIP) and ceftriaxone (CTR) tranferred its AMX and CIP resistance to the recipient $E$. coli $\mathrm{DH} 5 \mathrm{a}$, that was previously sensitive to all antibiotics. After transformation, the recipient $E$. coli $\mathrm{DH} 5 a$ became resistant to CIP and AMX, while the donor showed resistance to gentamycin $(\mathrm{CN})$, ceftriaxone (CTR), amoxicillin (AMX), ciprofloxacin (CIP), cefixime $\mathrm{CFM}$, and cotrimoxazole (COT). Plasmid extracted from the transformant revealed that, three genes ( $3 \mathrm{~kb}, 5 \mathrm{~kb}$ and $20 \mathrm{~kb})$ have been transferred from the donor to recipient.

Conclusion: Plasmids responsible for amoxicillin and ciprofloxacin were transferred.
Keywords: Antimicrobial resistance; Horizontal plasmid transfer; MDR; UTI

\section{Introduction}

Urinary tract infection (UTI), usually caused by Escherichia coli, is the most common bacterial infection in humans. The risk factors for UTIs include sexual activity, gender, genetics and presence of urinary catheters $[1,2]$. Females are more prone to UTIs than male because their urethra is much shorter and closer to the anus. Females further lack the bacteriostatic properties of prostatic secretions [1].

E. coli causing UTI belongs to several subgroups that are selected by some factors, which enhance extra intestinal survival. These factors include structural features such as fimbriae or pili for adherence, flagella for motility and chemical adhesion [3]. The type-1 pili of uropathogenic $E$. coli are known to be associated with increased severity of UTI by binding to mannose containing glycoprotein receptors on facet cells lining the bladder or vaginal epithelial cells [4]. Other virulence factors which confer the ability to fecal E. coli to colonize the vaginal mucosa and cause symptomatic UTI have also been identified [3]. However, the ability of E. coli to cause UTIs is increasing, while the ease of treating these infections due to resistance to first generation antibiotics such as cotrimoxazole, ampicillin and nitrofuranton is becoming progressively more elusive. The greater concern is the recent increase in resistance to second or even third generation antibiotics such as ciprofloxacin, levofloxacin and ceftriaxone $[2,5,6]$.

From studies of the following few decades, it has been clear that multidrug resistance phenomena is due to chromosomal genetic elements as well as existing plasmids and their association with other genetic mobile elements. In Japan, the role of plasmids in antibiotic resistance was first recognized by Watanabe and Fukasawa in 1961 [7]. Their report shows that transfer of a plasmid, which is known as resistance transfer factor or R-factor, that carries the resistance genes, is a single step process. Further reports showed that plasmids were carriers of not only multi-drug resistance genes, but also genes associated to contribute to the virulence of the host bacteria $[8,9]$.

Antibiotic resistant bacterial infection has been identified as one of the greatest epidemic threats to human health by the World Health Organization. Within this epidemic, a group of pathogens has been individualized and collectively named ESKAPE (Enterococcus faecium, Staphylococcus aureus, Klebsiella pneumoniae, Acinetobacter baumannii, Pseudomonas aeruginosa, and Enterobacter). These are opportunistic pathogens; the majority of them cause hospital- acquired infection that is resistant to antibiotic treatment. Plasmids play a 
central role in the dissemination and acquisition of the resistant determinants in these bacteria [10].

The increasing ability of $E$. coli to cause UTIs and the difficulty encountered in treating these infections due to multidrug resistance necessitates updating the knowledge of their drug resistance in a given environment. Horizontal gene transfer between bacterial cells contributes to bacterial adaptation to various environments and, in the long term, to bacterial evolution [11]. In human environments, it results in the undesirable spread of pathogenic, antibiotic resistance, or artificially engineered genes. Three mechanisms of horizontal gene transfer in bacteria are generally known: conjugation, transduction and transformation. Conjugation and transduction involve specific apparatus for DNA transfer from donor cells to recipient cells; they are conjugative pili and phage capsids, respectively. However, transformation is mainly performed by the recipient cells that express genetic competence to take up extracellular free DNA [12]. Competence for transformation can be induced naturally and artificially but not all bacterial species develop natural competence.

$E$. coli is not assumed to be naturally transformable; it develops high genetic competence only under artificial conditions, e.g. exposure to high $\mathrm{Ca}^{2+}$ concentrations [13]. However, several reports have shown that $E$. coli can express modest genetic competence in certain conditions that can arise in its environment and make it subjected to horizontal transformation $[11,12,14]$. We herein report that inheritance of antibiotic resistance occurs due to transconjugation or transformation of plasmids. It has been further discussed that a particular plasmid is responsible for resistance against a specific antibiotic.

\section{Materials and Methods}

\section{$E$. coli isolates and their maintenance}

The multi-drug resistant $E$. coli isolates were obtained from urine samples of UTI patients in North East region of Bangladesh [2]. E. coli isolates were identified based on morphological, cultural and biochemical characteristics as described by Cappuccino et al. [15] and Bergey's manual of systematic bacteriology [16]. The reference strain, $E$. coli $\mathrm{DH} 5$ a, was collected from department of microbiology, University of Dhaka, Bangladesh. The pure culture of $E$. coli isolates and E. coli $\mathrm{DH} 5$ a was routinely sub-cultured on nutrient agar. The pure culture was preserved at $-30^{\circ} \mathrm{C}$ with $20 \%$ glycerol.

\section{The plasmid transfer in $E$. coli DH5a through conjugation}

A single colony of multidrug resistant $E$. coli isolate (donor) and that of antibiotic sensitive E. coli $\mathrm{DH} 5 \alpha$ (recipient) were inoculated into Luria broth (LB) separately and incubated in a shaker at $37^{\circ} \mathrm{C}$ for overnight. Five hundred micro litre of donor and recipient cultures was added to $4 \mathrm{ml}$ fresh $\mathrm{LB}$ and incubated overnight at $37^{\circ} \mathrm{C}$ without shaking [17]. A 10-fold serial dilution was then done with LB and 100 $\mu \mathrm{l}$ from each dilution was plated into sorbitol-MacConkey agar (SMAC medium) [18] containing selected antibiotics. SMAC medium was used as a differential color forming medium for detection of sorbitol fermenting (donor) isolate with characteristic red to colorless colonies and non-sorbitol-fermenting (recipient) isolate with characteristic colorless colonies. In SMAC, the lactose of MacConkey agar was replaced by sorbitol. After conjugation, the recipient $E$. coli DH5a transformed with plasmid produced pink colonies on the antibiotic selection plate.

\section{Extraction and purification of plasmids}

Plasmids were extracted by mini alkaline lysis method [19] from 16 h cultured cells of $E$. coli. Plasmids were then subjected to electrophoresis onto $0.7 \%$ agarose gel using standard protocol. The gels stained with ethidium bromide were visualized on an ultraviolet transilluminator (UVP, High Performance transilluminator; USA) and recorded with a canon camera (PowerShort A3200 IS). A particular plasmid band was excised from the gel and purified with the FavorPrep ${ }^{\text {Tw }}$ plasmid DNA extraction mini kit (Favorgen Biotech Corp., Taiwan).

\section{Competent cell preparation, plasmid transformation and antibiotic susceptibility}

Competent cells of E. coli DH5a were prepared as described by Sambrook et al. [19]. For transformation, $50 \mu \mathrm{l}$ of plasmid DNA was added to a tube containing $0.2 \mathrm{ml}$ of competent cells. The mixture was placed on ice for $20 \mathrm{~min}$, and then exposed to heat shock at $42^{\circ} \mathrm{C}$ for 1 min and kept immediately in ice for $10 \mathrm{~min}$. A $800 \mu \mathrm{LB}$ broth was then added to transformation mixture and incubated at $37^{\circ} \mathrm{C}$ for 60 min. About $100 \mu \mathrm{l}$ from transformation mixture was spread on nutrient agar plates containing the appropriate antibiotic. An aliquot (100 $\mu$ of 5-10 fold diluted) of competent cells spread on nutrient agar containing the same antibiotics was used as a control. All plates were incubated at $37^{\circ} \mathrm{C}$ for $48 \mathrm{~h}$. The transformant colonies were scored and fresh cultured several times on plates containing the desired antibiotics. The transformant was investigated for the presence of target plasmid. The susceptibility of transformant and nontransformant $E$. coli $\mathrm{DH} 5$ a to different antibiotics was investigated by the modified Kirby-Bauer disc diffusion method [20].

\section{Results}

\section{Inherence of antibiotic resistance in $E$. coli DH5a through conjugation}

E. coli isolate resistant to amoxicillin (AMX), ceftriaxone (CTR) and ciprofloxacin (CIP) and E. coli DH5a sensitive to these antibiotics were used as donor and recipient, respectively (Figure $1 \mathrm{~A}$ and $\mathrm{B}$ ).



Figure 1: Antibiogram of E. coli isolate and E. coli DH5a. E. coli isolate was resistance to AMX, CTR and CIP (A), whereas E. coli DH5 $\alpha$ was sensitive to all antibiotics investigated (B).

SMAC media was used for selecting the transconjugants. The donor E. coli isolate produced red to pink colonies (Figure 2A) due to acid production by fermentation of sorbitol in the media. The recipient $E$. coli DH5a cannot ferment sorbitol, and use peptone instead [17]. This forms ammonia, which raises the $\mathrm{pH}$ of the agar and lead to the formation of white/colorless colonies (Figure 2B). 
Citation: Suhani S, Purkaystha A, Begum MK, Islam MJ, Azad AK (2017) Plasmids for Amoxicillin and Ciprofloxacin Resistance in Escherichia coli Isolate Causing Urinary Tract Infection. Clin Microbiol 6: 284. doi:10.4172/2327-5073.1000284

Page 3 of 5

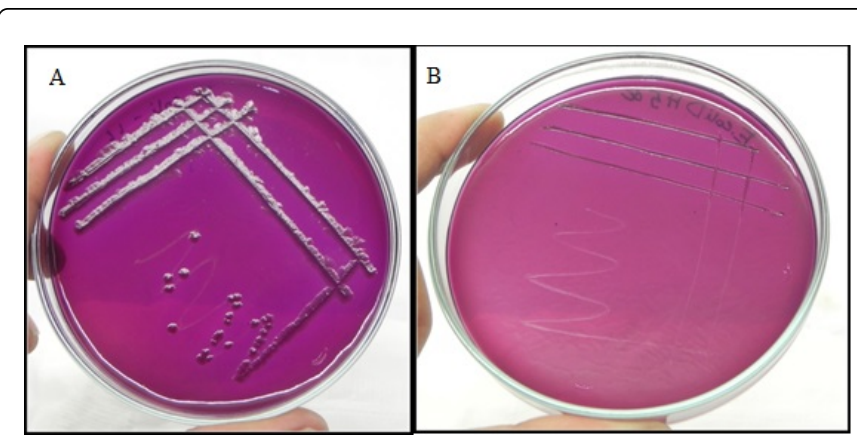

Following conjugation, less-whitish colonies of E. coli DH5a were observed on SMAC media in the presence of AMX and CIP (Figure 3A and B) but not in the presence of CTR (Figure 3C). Growth of E. coli $\mathrm{DH} 5 \mathrm{a}$ in the presence of AMX and CIP indicated that resistance to these antibiotics was inherited to them due to transfer of plasmid form the donor through conjugation.

Figure 2: Cultural characteristics of $E$. coli isolate (A) and $E$. coli DH5a (B) on SMAC.

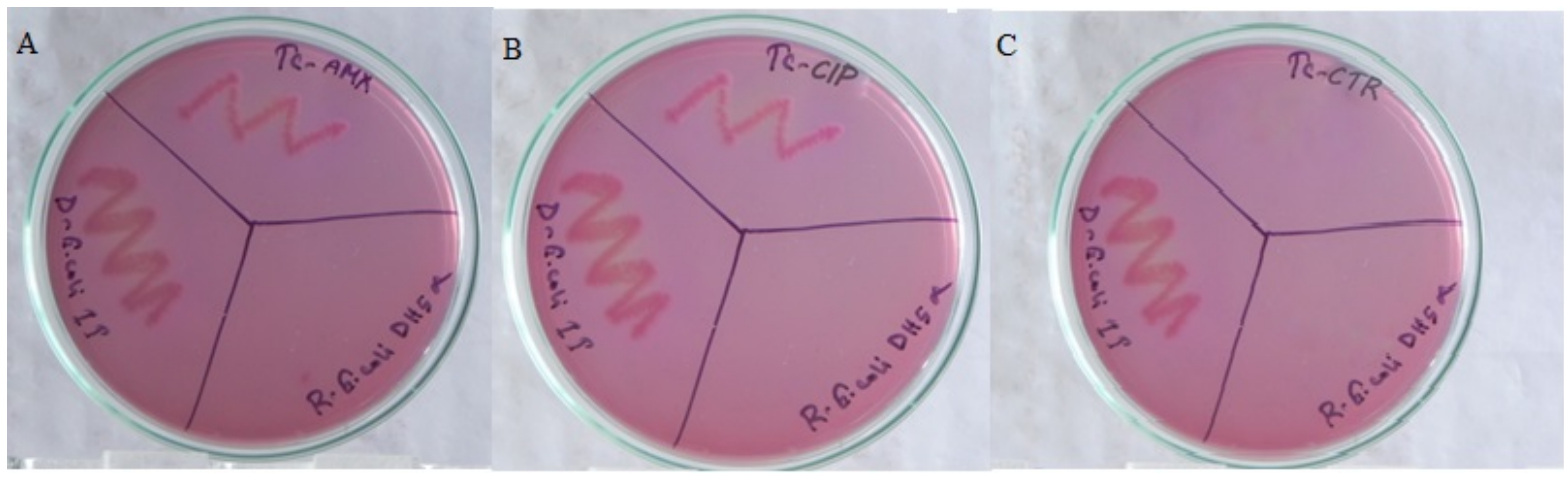

Figure 3: Growth of the donor, recipient and transconjugant on SMAC media containing AMX (A), CIP (B) and CTR (C).

\section{Plasmid DNA transformation makes $E$. coli DH5a resistant} to AMX and CIP

After plasmid DNA transformation, the transformant E. coli DH5a was screened in the presence of AMX and CIP separately. It was observed that some transformants could grow in the presence of these two antibiotics (Figure 4A-D).
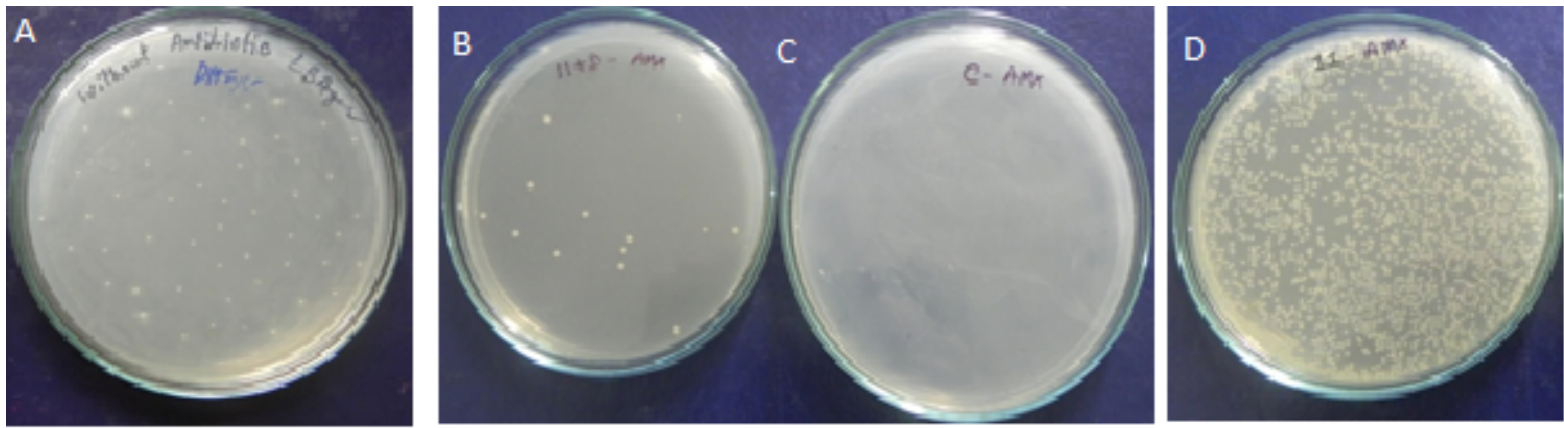

Figure 4: Selection of transformants in nutrient agar containing AMX (A) Growth of E. coli DH5a without AMX (positive control), (B) transformant growing in the media containing AMX, (C) no growth of E. coli DH5a in the presence of AMX (negative control), (D) growth of donor in the presence of AMX.

After selection in the media containing antibiotic, the transformants were subjected to antibiogram of some antibiotics to determine which antibiotic resistant gene had been transferred to transformant $E$. coli DH5a. For this, eight antibiotic disks were used to compare the susceptibility of the transformants (Figure 5B) to that of E. coli DH5a (Figure 5C) and multidrug resistant E. coli isolate from which plasmid was extracted (Figure 5A). 


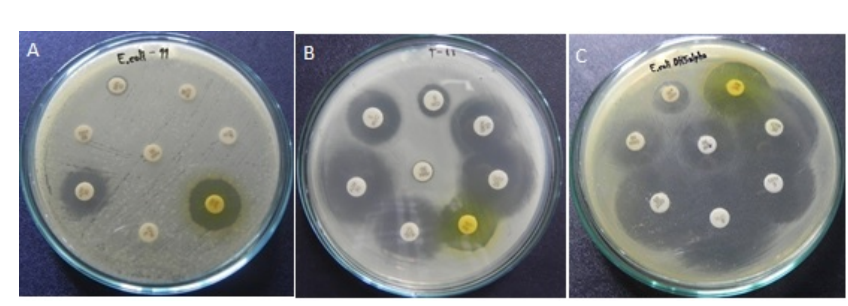

Figure 5: Antibiogram of $E$. coli isolate (A), transformant (B) and $E$. coli $\mathrm{DH} 5 \mathrm{a}(\mathrm{C})$.

It was observed that the MDR E. coli isolates were resistant to six antibiotics and $E$. coli DH5a was sensitive to all antibiotics. The transformant $E$. coli DH5a inherited resistance to two antibiotics, CIP and AMX. This result indicated that CIP and AMX resistance genes might have been transferred to E. coli $\mathrm{DH} 5$ a.

\section{Plasmid profiling of transconjugates and transformants}

Plasmids were isolated from the donor or MDR E. coli isolate, transconjugates, transformants and recipient E. coli $\mathrm{DH} 5 \alpha$ and their plasmid profiling were compared. It was observed that the donor $E$. coli isolate harbored multiple plasmids of different sizes, whereas, the recipient E. coli DH5a had no plasmid (Figure 6).

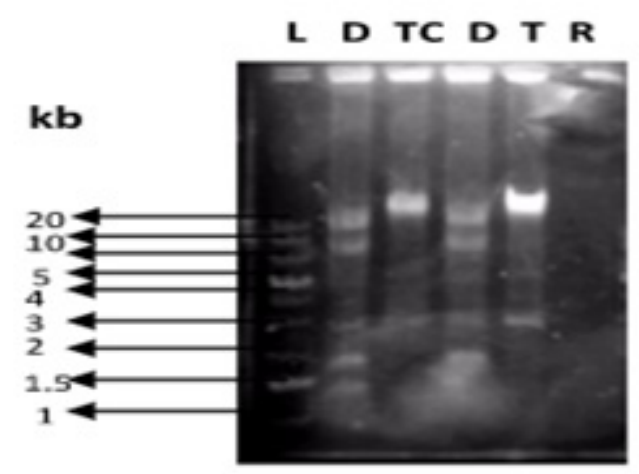

Figure 6: Electrogram of plasmids from donor (D, lanes 2 and 4), transconjugants (TC, lane 3 ), transformant (T, lane 5), recipient (R, lane 6); DNA ladder (L) is shown in lane 1.

However, AMX and CIP resistant transconjugates and transformants harbored plasmids of about $3 \mathrm{~kb}, 5 \mathrm{~kb}$ and $20 \mathrm{~kb}$, which were present in the donor or MDR E. coli isolate. This result indicated that the recipient or the competent cells obtained these plasmids during conjugation and transformation.

\section{Discussion}

The emergence, proliferation, aggregation, and management of antimicrobial-resistant pathogenic bacteria have become a worldwide health concern. When the resistance associated with the presence of transposable DNA elements, such as plasmids, it may be difficult to eliminate resistance, which tends to increase over time [21]. Our previous study depicted that $E$. coli isolates showing MDR were found to harbor multiple plasmids of different sizes and left an assumption that the MDR genes might be in the plasmid or chromosomal DNA [2]. It has been reported that Enterobacteriaceae isolates might be potential carrier of antibiotic resistant genes that could be transferred between bacterial strains of the same or different species of UTI pathogens [22-24]. In the present study, we investigated the plasmid associated antibiotic resistance in E. coli isolates causing UTI.

The present study showed that plasmids responsible for AMX and CIP resistance were transferred to the recipient E. coli DH5a. Many studies have shown that the dissemination of resistant genes mediated by plasmids may occur by conjugation [25-28].

Genetic transformation is an important mechanism of the horizontal exchange of genes. Natural genetic transformation is a gene transfer process where the bacteria can pick up the naked DNA from their environment and the DNA may come from a variety of sources. The most frequent source is remnants from dead bacterial cells. The exogenous DNA bind to specific cell surface receptors, then the DNA is transported across the membrane and one strand of the DNA is digested away. As a consequence, the single stranded DNA enters the cell. Recombination occurs between the incorporated DNA and homologous host DNA and the new DNA replaces a strand of the host DNA. This new DNA may contain noble and different genes compared to the host DNA, including antibiotic resistance gene [29]. An investigation carried out in the UK revealed that Enterobacteriaceae isolates from 43 hospitals during 1990-1991 showed antibiotic resistance due to plasmid DNA by transformation [30]. Another study reported transformation process responsible for chloramphenicol, tetracycline and sulfonamide resistance transferred with the CTX-M-1 enzyme as co-transformant [31].

The present study showed that three plasmids, eg. $3 \mathrm{~kb}, 5 \mathrm{~kb}$ and 20 $\mathrm{kb}$ were transferred to the recipient cell, and thereby, the recipient $E$. coli DH5a became resistant to CIP and AMX. However, the non transformant recipient cells remained sensitive to these antibiotics. These three or any of these plasmids might carry CIP and AMX resistance gene. This report reveals the spread of the plasmid mediated antibiotic resistant genes between $E$. coli isolates of UTI patient and $E$. coli DH5a. Nevertheless, further research is needed to determine the specific gene in these plasmids associated with CIP and AMX resistance.

\section{Conclusion}

Our study revealed that, following conjugation and transformation, amoxicillin and ciprofloxacin resistance was inherited by $E$. coli DH5a that was previously sensitive to all antibiotics, from the MRD E. coli isolates obtained from UTI patients. This finding indicates that, plasmids responsible for antibiotic resistance can be transferred among bacteria through horizontal gene transfer. Careful use of antimicrobial agents, developing standard treatment guidelines and increasing awareness among people can ensure proper health care and reduce the spread of antimicrobial resistance among bacteria.

\section{References}

1. Nicolle LE (2008) Uncomplicated urinary tract infection in adults including uncomplicated pyelonephritis. Urol Clin North Am 35(1): 1-12.

2. Rabbee MF, Begum MK, Islam MJ, Chowdhury PA, Chowdhury OA, et al. (2016) Multidrug Resistance Phenotype and Plasmid Profiling of Escherichia coli Isolates Causing Urinary Tract Infections in North East Part of Bangladesh. Br Microbiol Res J 15(6): 1-11. 
Citation: Suhani S, Purkaystha A, Begum MK, Islam MJ, Azad AK (2017) Plasmids for Amoxicillin and Ciprofloxacin Resistance in Escherichia coli Isolate Causing Urinary Tract Infection. Clin Microbiol 6: 284. doi:10.4172/2327-5073.1000284

Page 5 of 5

3. Emo L, Kerenyi M, Nagy G (2003) Virulence factors of uropathogenic Escherichia coli. Int J Antimicrob Agents 22: 29-33.

4. Venegas MF, Navas EL, Gaffney RA, Duncan JL, Anderson BE, et al. (1995) Binding of type 1-piliated Escherichia coli to vaginal mucus. Infection and immunity 63(2): 416-422.

5. Karlowsky JA, Hoban DJ, Decorby MR, Laing NM, Zhanel GG (2006) Fluoroquinolone-resistant urinary isolates of Escherichia coli from outpatients are frequently multidrug resistant: results from the North American Urinary Tract Infection Collaborative Alliance-Quinolone Resistance study. Antimicrob Agents Chemother 50(6): 2251-2254.

6. Hooton TM (2000) Pathogenesis of urinary tract infections: an update. J Antimicrob Chemother. 46(suppl 1): 1-7.

7. Watanabe T, Fukasawa T (1961) Episome-Mediated Transfer of Drug Resistance In Enterobacteriaceae I: Transfer of Resistance Factors by Conjugation. J Bacteriol 81(5): 669.

8. Watanabe $\mathrm{T}$ (1963) Infective heredity of multiple drug resistance in bacteria. Bacteriol Rev 27(1): 87.

9. Ramirez MS, Traglia GM, Lin DL, Tran T, Tolmasky ME (2014) Plasmidmediated antibiotic resistance and virulence in gram-negatives: the Klebsiella pneumoniae paradigm. Microbiol Spectr 2(5): 1 .

10. Boucher HW, Talbot GH, Benjamin DK, Bradley J, Guidos RJ, et al. (2013) $10 \times 20$ progress-development of new drugs active against gramnegative bacilli: an update from the Infectious Diseases Society of America. Clin Infect Dis 56(12): 1685-1694.

11. Thomas CM, Nielsen KM (2005) Mechanisms of, and barriers to, horizontal gene transfer between bacteria. Nat Rev Microbiol 3(9): 711-721.

12. Keese P (2008) Risks from GMOs due to horizontal gene transfer. Environ Biosafety Res 7(3): 123-149.

13. Méjean V, Claverys JP (1993) DNA processing during entry in transformation of Streptococcus pneumoniae. J Biol Chem 268(8): 5594-5599.

14. Lorenz MG, Wackernagel W (1994) Bacterial gene transfer by natural genetic transformation in the environment. Microbiol Rev 58(3): 563-602.

15. Cappuccino J, Sherman N (2001) Microbiology: A Laboratory Manual.

16. Whitman W, Goodfellow M, Kämpfer P, Busse HJ, Trujillo $\mathrm{M}$, et al. (2012) The Actinobacteria Bergey's Manual of Systematic Bacteriology: Volume 5 Springer Science \& Business Media.

17. Wang A, Yang Y, Lu Q, Wang Y, Chen Y, et al. (2008) Presence of qnr gene in Escherichia coli and Klebsiella pneumoniae resistant to ciprofloxacin isolated from pediatric patients in China. BMC Infect Dis 8(1): 68.

18. March SB, Ratnam SA (1986) Sorbitol-MacConkey medium for detection of Escherichia coli O157: H7 associated with hemorrhagic colitis. J Clin Microbiol 23(5): 869-872.
19. Sambrook J, Russell D (2001) Molecular Cloning: A Laboratory manual. (3 732 volume set), Cold Spring Harbor Laboratory Press, 2344.

20. Bauer AW, Kirby WM, Sherris JC, Turck M (1966) Antibiotic susceptibility testing by a standardized single disk method. Am J Clin Pathol 45(4): 493.

21. Kazemnia A, Ahmadi M, Dilmaghani M (2014) Antibiotic resistance pattern of different Escherichia coli phylogenetic groups isolated from human urinary tract infection and avian colibacillosis. Iran Biomed J 18(4): 219.

22. Österblad M, Hakanen A, Manninen R, Leistevuo T, Peltonen R, et al. (2000) A between-species comparison of antimicrobial resistance in enterobacteria in fecal flora. Antimicrob Agents Chemother 44(6): 1479-1484.

23. Lawrence JG (2005) Horizontal and vertical gene transfer: the life history of pathogens, in Concepts in Bacterial Virulence. Contrib Microbiol 12: 255-271.

24. Tenover FC (2006) Mechanisms of antimicrobial resistance in bacteria. The American journal of medicine. Am J Med 119(6): S3-S10.

25. Aluyi H, Akortha E (2002) Transfer of ampicillin resistance gene (ampr) from some enteric bacteria of diarrhoeal origin to Escherichia coli (UBE201). J Med Lab Sci 11(2): 39-41.

26. Díaz MA, Cooper RK, Cloeckaert A, Siebeling RJ (2006) Plasmidmediated high-level gentamicin resistance among enteric bacteria isolated from pet turtles in Louisiana. Appl Environ Microbiol 72(1): 306-312.

27. Ferguson GC, Heinemann JA, Kennedy MA (2002) Gene transfer between Salmonella enterica serovar Typhimurium inside epithelial cells. J Bacteriol 184(8): 2235-2242.

28. Shoemaker NB, Vlamakis H, Hayes K, Salyers AA (2001) Evidence for Extensive Resistance Gene Transfer amongBacteroides spp. and among Bacteroides and Other Genera in the Human Colon. Appl Environ Microbiol 67(2): 561-568.

29. Navarro F (2010) Acquisition and horizontal diffusion of $\beta$-lactam resistance among clinically relevant microorganisms. Int Microbiol 9(2): 79-81.

30. Piddock LJ, Walters RN, Jin YF, Turner HL, Gascoyne-Binzi DM, et al. (1997) Prevalence and mechanism of resistance to'thirdgeneration'cephalosporins in clinically relevant isolates of Enterobacteriaceae from 43 hospitals in the UK, 1990-1991. J Antimicrob Chemother 39(2): 177-187.

31. Arpin C, Dubois V, Coulange L, André C, Fischer I, et al. (2003) Extended-spectrum $\beta$-lactamase-producing Enterobacteriaceae in community and private health care centers. Antimicrob Agents Chemother 47(11): 3506-3514. 